Daniel C. Broom • Emily M. Jutkiewicz • John E. Folk • John R. Traynor $\cdot$ Kenner C. Rice $\cdot$ James H. Woods

\title{
Convulsant activity of a non-peptidic $\delta$-opioid receptor agonist is not required for its antidepressant-like effects in Sprague-Dawley rats
}

Received: 28 December 2001 / Accepted: 26 May 2002 / Published online: 30 July 2002

(C) Springer-Verlag 2002

\begin{abstract}
Rationale: Non-peptidic $\delta$-opioid receptor agonists possess antidepressant-like activity in the forced swim assay in the rat. These compounds have also previously been shown to possess convulsant properties in mice. Objective: The aim of the present study was to examine whether such convulsions occurred in rats and to investigate if $\delta$-mediated convulsant activity was necessary for the mediation of $\delta$-opioid agonist-induced antidepressant-like activity. Methods: The peripheral administration of $\delta$-opioid receptor agonists to male Sprague-Dawley rats was followed by a period of observation for convulsant activity. Following this period and $60 \mathrm{~min}$ after $\delta$-opioid agonist administration, rats were tested in the forced swim assay. Results: The nonpeptidic $\delta$-opioid receptor agonists $(+)-4-[(\mathrm{R})-[(2 \mathrm{~S}, 5 \mathrm{R})-$ 2,5-dimethyl-4-(2-propenyl)-1-piperazinyl]-(3-methoxyphenyl)methyl]-N,N-diethylbenzamide (SNC80) and (+)-4-[(R)-[(2S,5R)-2,5-dimethyl-4-(2-propenyl)-1-piperazinyl]-(3-hydroxyphenyl)methyl]-N,N-diethylbenzamide dihydrochloride [(+)BW373U86] both produced dosedependent convulsant activity in rats and decreased immobility in the forced swim assay. The $\delta$-opioid receptor antagonist naltrindole prevented the convulsant activity of (+)BW373U86 and its effects in the forced swim assay. This suggested a $\delta$-opioid mechanism for both effects. Midazolam prevented convulsions but did not prevent activity in the forced swim assay. Rats tolerant to the convulsive effects of (+)BW373U86 still displayed antidepressant-like effects. Conclusion: $\delta$-Me-
\end{abstract}

D.C. Broom · E.M. Jutkiewicz · J.R. Traynor · J.H. Woods $(\bowtie)$ Department of Pharmacology,

University of Michigan Medical School,

1301 Medical Science Research Building III, Ann Arbor,

MI 48109-0632, USA

e-mail: jhwoods@umich.edu

Fax: +1-734-7647118

J.H. Woods

Department of Psychology, University of Michigan, Ann Arbor, Mich., USA

J.E. Folk · K.C. Rice

NIDDK, National Institutes of Health, Bethesda, Md., USA diated convulsions do occur in rats and can be prevented without affecting the $\delta$-mediated effects in the forced swim assay. Therefore the convulsant activity of (+)BW373U86 and possibly other non-peptidic $\delta$-agonists is not required for activity in the forced swim assay.

Keywords $\delta$-Opioid receptor - Forced swim assay . Depression · Convulsions · (+)BW373U86 - SNC80

\section{Introduction}

A number of studies have implicated $\delta$-opioid receptor systems in depression and animal models of depression. These studies include the antidepressant effects of enkephalinase inhibitors such as RB101 and BL-2401 (Baamonde et al. 1992; Kita et al. 1997) in learned helplessness paradigms. The effects of RB101 in this procedure were subsequently found to be prevented with the $\delta$-opioid receptor selective antagonist naltrindole (Tejedor-Real et al. 1998). Additionally, mice lacking the $\delta$-opioid receptor displayed behavior in standard antidepressant screening assays consistent with a depressive profile (Filliol et al. 2000). Most recently, studies have shown that rats treated with the non-peptidic $\delta$ opioid receptor agonists, (+)-4-[(R)-[(2S,5R)-2,5-dimethyl-4-(2-propenyl)-1-piperazinyl]-(3-methoxyphenyl)methyl]-N,N-diethylbenzamide (SNC80) and (+)-4-[(R)[(2S,5R)-2,5-dimethyl-4-(2-propenyl)-1-piperazinyl]-(3hydroxyphenyl)methyl]-N,N-diethylbenzamide dihydrochloride [(+)BW373U86], show decreased immobility and increased activity counts in both the Porsolt forced swim assay and in a modified forced swim assay with only one pool exposure (Broom et al. 2002), an effect prevented by naltrindole. The effects of these $\delta$-agonists in the forced swim assay were dissociable from increases in locomotor activity and small changes in core body temperature. These data also strongly suggest that $\delta$ opioid receptor agonists may have antidepressant-like activity. 
Endogenous opioid systems have been implicated in the mechanism of action of electroconvulsive shock (ECS). For example, the activity of endogenous opioids such as $\beta$-endorphin have been shown to increase following ECS (Emrich et al. 1979; Inturrisi et al. 1982). In this regard, $\delta$-opioid receptor agonists may increase endogenous opioids as the selective non-peptidic $\delta$-agonists BW373U86 (Chang et al. 1993) and SNC80 (Calderon et al. 1994; Bilsky et al. 1995) produce convulsant activity in mice (Comer et al. 1993; Hong et al. 1998). In all cases, the convulsions observed in mice were short and non-lethal, occurred a few minutes after systemic injection of the compound, and were prevented by pretreatment with naltrindole. The convulsant episode was followed by Straub tail and a brief period of catalepsy.

There are very few reports of convulsions following administration of non-peptidic $\delta$-opioid receptor agonists in species other than mice. BW373U86 produces convulsions in squirrel monkeys (Dykstra et al. 1993; Pakarinen et al. 1995) and there is one report of a convulsion in a rhesus monkey (Negus et al. 1994). Spina and colleagues (1998) reported no convulsions in rats treated with BW373U86 and SNC80, although wet-dog shakes and "falling on the back" were seen with the highest doses of the drugs used. However, in preliminary experiments we observed convulsions in rats after injection of (+)BW373U86 or SNC80 (Broom et al. 2002); the doses used in our experiments were higher than those studied by Spina and coworkers.

The possible interaction between $\delta$-mediated convulsant and antidepressant-like effects is intriguing. It may be postulated that, if dose-dependent $\delta$-opioid-mediated convulsant activity occurs in rats as it does in mice, then this convulsant activity may contribute to the antidepressant-like activity of these compounds in the forced swim assay through an ECS-like mechanism of action. The aim of the present study was to characterize pharmacologically the convulsant effects of the non-peptidic $\delta$-opioid receptor agonist $(+)$ BW373U86 in rats. Further, the relation of the convulsant activity of this compound to antidepressant-like activity was examined to determine if $\delta$-mediated convulsions are necessary for the $\delta$-mediated antidepressant-like activity. The convulsant properties of $\delta$-opioid receptor agonists were determined in rats before using the forced swim assay as a predictive measure of antidepressant activity. Typical antidepressants produce a profile of action in rats consisting of a decrease in immobility (Porsolt et al. 1977) that is correlated with an increase in one or both of two forms of activity, swimming or climbing, when compared to control animals (Detke et al. 1995; Reneric and Lucki 1998). By comparing $\delta$-mediated convulsant effects to antidepressant-like effects within a group of rats, it was possible to ascertain the necessity of the convulsion for subsequent antidepressant-like activity. In addition, it has been observed that $\delta$-opioid mediated convulsions in mice may be reduced by midazolam or repeated administration of agonist (e.g. Hong et al. 1998). These effects were examined in rats on both the convulsant and swimming effects of $\delta$-agonists.

\section{Materials and methods}

\section{Chemicals}

(+)BW373U86.2 $\mathrm{HCl}$ was synthesized according to standard protocols (Bishop et al. 1995) and was dissolved in sterile water. Naltrindole hydrochloride (Dr. J. Lewis, University of Bath, UK) and desipramine hydrochloride (Sigma, St. Louis, Mo., USA) were dissolved in sterile water. Midazolam (Bedford Laboratories, Bedford, Ohio, USA) was dissolved in sterile saline. SNC80 base was synthesized according to standard protocols (Calderon et al. 1994) and dissolved in sterile water using a drop of $1 \mathrm{~N}$ hydrochloric acid.

\section{Animals}

Male Sprague-Dawley rats (200-350 g) were obtained from Harlan (Indianapolis, Ind., USA) and housed in groups of three to four animals. All animals were fed a standard laboratory diet and kept on a 12-h light/dark cycle with lights on at 0630 hours at a temperature of $21^{\circ} \mathrm{C}$. Studies were performed in accordance with the Declaration of Helsinki and with the Guide for the Care and Use of Laboratory Animals as adopted and promulgated by the National Institutes of Health. The experimental protocols were approved by the University of Michigan University Committee on the Use and Care of Animals.

\section{Convulsant activity}

The measurement of convulsant activity was performed as previously described for mice (Comer et al. 1993; Broom et al. 2000). Male Sprague-Dawley rats were injected subcutaneously (SC) with test drug [SNC80 or (+)BW373U86] and placed in individual Plexiglas boxes for the duration of the observation period. Rats were observed for convulsant activity for $20 \mathrm{~min}$ after drug injection. Convulsant activity generally occurred as clonic movements of the head, face and forepaws and sometimes involved rearing. Postconvulsion catalepsy was assessed by placing the forepaws of the rat on a horizontal rod; a positive catalepsy score was assigned if the rat did not remove its paws within $15 \mathrm{~s}$. Catalepsy was also tested via loss of righting by placing the rat on its back. Catalepsy was not required for a positive convulsive score. Data were expressed as percentage of the number of animals convulsing.

\section{Forced swim assay}

For a measure of antidepressant-like activity, rats were subjected to the forced swim assay modified from that previously described by Detke and colleagues (1995). Briefly, male Sprague-Dawley rats $(200-350 \mathrm{~g})$ were placed in a cylindrical Plexiglas container $(46 \mathrm{~cm}$ tall $\mathrm{x} 20 \mathrm{~cm}$ diameter) filled to $30 \mathrm{~cm}$ with $25^{\circ} \mathrm{C}\left( \pm 1^{\circ} \mathrm{C}\right)$ water. As antidepressant-like activity has previously been demonstrated during initial pool exposure (Broom et al. 2002), one swimming session was conducted, lasting $15 \mathrm{~min}$. An aerial view of the swim was videotaped for later analysis and scoring. Cylinder water was changed after every rat. Following each swim period, the rats were removed from the water, towel-dried, and placed in a heated cage for $15 \mathrm{~min}$.

Scoring was performed by an observer blind to the treatment received by each animal. The behavior of the rats was analyzed every $5 \mathrm{~s}$ for 5-min periods during the swim. Behavior was classified as one of three behaviors: immobility, swimming, or 
climbing (Detke et al. 1995). Immobility was defined as floating in the water without struggling and using only small movements to keep the head above water. Swimming was defined as moving limbs in an active manner (more than required to keep the head above water) causing movement among quadrants of the cylinder. Finally, climbing was defined as making active movements with forepaws moving in and out of the water, usually directed against the side of the cylinder. The numbers of each behavior counted during each 5-min period were totaled and averaged within each treatment group. The activity scores for the total $15 \mathrm{~min}$ were also calculated. Statistical analysis was performed using one-way ANOVA with Dunnett's post-hoc test (Graphpad Prism software). $P<0.05$ was accepted as statistical significance.

Drug treatment

Desipramine was administered by intraperitoneal (IP) injection. All other drugs were administered by subcutaneous (SC) injection. For all swim experiments, a single dose of desipramine, $(+)$ BW373U86 or vehicle control was injected $1 \mathrm{~h}$ before the swim. For tolerance experiments $(+)$ BW373U86 was injected $25 \mathrm{~h}$ and again $1 \mathrm{~h}$ prior to the swim. Naltrindole was administered $30 \mathrm{~min}$ prior to agonist treatment (i.e. $90 \mathrm{~min}$ before the swim) and midazolam was administered $15 \mathrm{~min}$ prior to agonist treatment (i.e. 75 min before the swim).

\section{Results}

Since known antidepressants have not been evaluated in this modified forced swim assay, $10 \mathrm{mg} / \mathrm{kg}$ desipramine was administered to a group of animals once $1 \mathrm{~h}$ prior to the 15-min swim period. Desipramine produced a significant decrease in immobility counts $[F(2,15)=7.18, P<0.01]$ and a significant increase in climbing $[F(2,15)=6.19, P<0.05]$ over the total $15-\mathrm{min}$ swim period (Fig. 1). Therefore, desipramine was seen to have an antidepressant-like effect in this modified forced swim assay protocol.

The non-peptidic $\delta$-opioid receptor agonists (+)BW373U86 and SNC80 both produced dose-dependent convulsant activity in rats (Fig. 2a). Occasionally, isolated myoclonic jerks of the forepaws preceded the clonic convulsion. Convulsions occurred as single episodes of clonic contractions of the musculature of the face, head and forepaws and sometimes involved rearing. The convulsive episode generally lasted for approximately $30-60 \mathrm{~s}$. Following the clonic convulsion, rats became cataleptic for a short period of time (approximately 2-4 min in duration). (+)BW373U86 was approximately 3- to 10 -fold more potent than SNC80 at producing the convulsant activity with both drugs producing responses in all animals. Time to convulsion tended to decrease with increasing dose of $(+)$ BW373U86 (Fig. 2b); however, this trend was not statistically significant $[F(2,21)=2.89, P=0.08]$. The $\delta$ opioid receptor antagonist naltrindole at a dose of $1 \mathrm{mg} /$ $\mathrm{kg}$ (SC) prevented the convulsions and catalepsy produced by administration of $10 \mathrm{mg} / \mathrm{kg}(+) \mathrm{BW} 373 \mathrm{U} 86$ (Fig. 3a).

In the forced swim assay, when compared to vehicle, $(+)$ BW373U86 $(10 \mathrm{mg} / \mathrm{kg})$ produced a significant de-

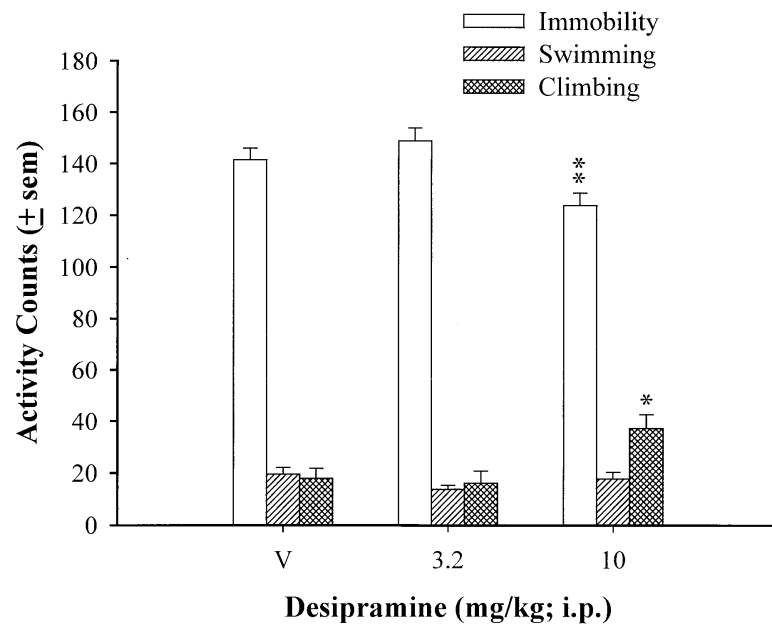

Fig. 1 The effect of desipramine on forced swimming activity in rats. Male Sprague-Dawley rats were injected with vehicle, $3.2 \mathrm{mg} /$ $\mathrm{kg}$ or $10 \mathrm{mg} / \mathrm{kg}$ desipramine (IP) and then tested 60 min later in the forced swim assay as described in Materials and methods. Results from the forced swim assay are displayed for the total 15-min swim period. $n=6$ for each group. $* P<0.05$ and $* * P<0.01$ when compared to vehicle $(V)$ alone by Dunnett's post-hoc analysis
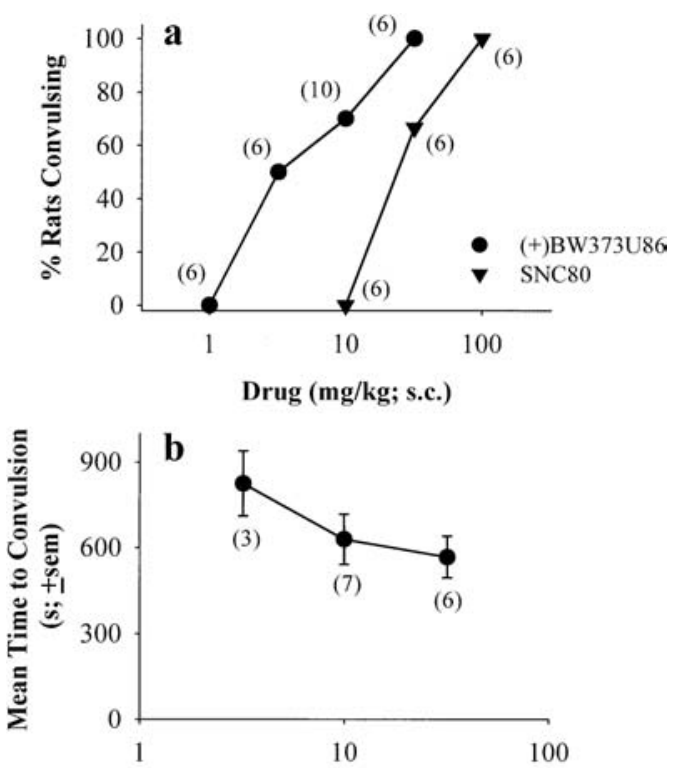

(+)BW373U86 (mg/kg; s.c.)

Fig. 2 a The convulsant activity of (+)BW373U86 and SNC80. Drug was administered by subcutaneous injection to male SpragueDawley rats. Convulsant activity was determined as described in Materials and methods. All points represent acute dosing of separate groups of rats. b Latency to convulsion in rats that convulsed at each dose of (+)BW373U86. Only data from rats that convulsed were included. Number in parentheses represents the number of rats observed

crease in immobility over the total 15 -min period $[F(3,20)=23.13, P<0.0001]$ (Fig. $3 b$ ) as well as individually during the first $[F(3,20)=17.48, P<0.0001]$ (Fig. 3c), second $[F(3,20)=27.12, P<0.0001]$ (Fig. 3d) and third 

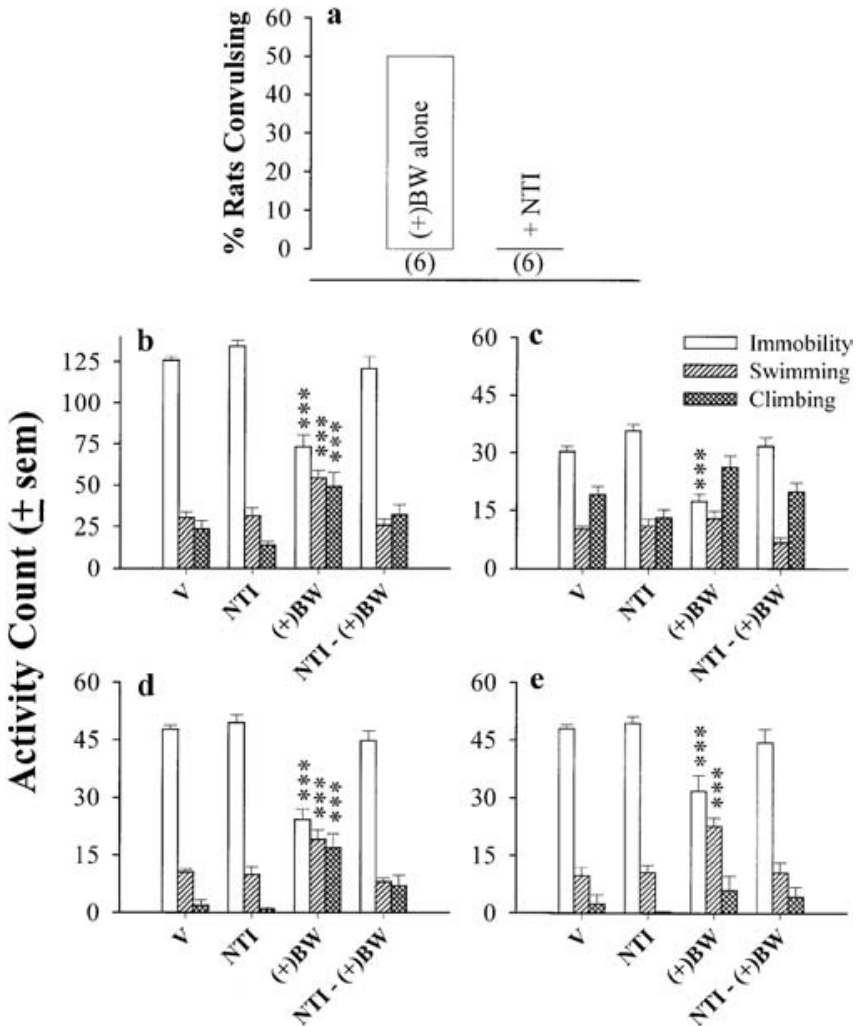

Fig. 3 The effect of naltrindole (NTI) on (+)BW373U86 [(+)BW]mediated $\mathbf{a}$ convulsions and $\mathbf{b}-\mathbf{e}$ forced swimming activity in rats. Male Sprague-Dawley rats were injected with $1 \mathrm{mg} / \mathrm{kg}$ NTI (SC) followed $30 \mathrm{~min}$ later with $10 \mathrm{mg} / \mathrm{kg}(+) \mathrm{BW} 373 \mathrm{U} 86$ (SC). Rats were observed for convulsive behavior for $20 \mathrm{~min}$ and then tested 60 min after $(+)$ BW373U86 injection in the forced swim assay as described in Materials and methods. Results from the forced swim assay are displayed for $\mathbf{b}$ the total $15-\mathrm{min}$ swim period and $\mathbf{c}$ the first 5-min, $\mathbf{d}$ second 5-min and e third 5-min periods individually. Treatment groups are as follows: $V$ NTI vehicle followed by (+)BW373U86 vehicle; NTI $1 \mathrm{mg} / \mathrm{kg}$ NTI followed by (+)BW373U86 vehicle; $(+) B W$ NTI vehicle followed by $10 \mathrm{mg} /$ $\mathrm{kg}(+)$ BW373U86; NTI-(+)BW $1 \mathrm{mg} / \mathrm{kg}$ NTI followed by $10 \mathrm{mg} / \mathrm{kg}$ (+)BW373U86. $n=6$ for each group. $* * * P<0.001$ when compared to vehicle $(V)$ alone by Dunnett's post-hoc analysis

$[F(3,20)=7.48, P<0.01]$ (Fig. 3e) 5-min periods. This effect was coupled to an increase in swimming during the total 15 -min swim period $[F(3,20)=8.98, p<0.001]$, the second 5-min $[F(3,20)=8.36, P<0.001]$ and third 5-min periods $[F(3,20)=7.29, P<0.01]$. An increase in climbing was also seen over the total 15-min swim period $[F(3,20)=8.98, P<0.001]$ as well as the second 5-min period $[F(3,20)=15.32, P<0.0001]$. A significant change in climbing was seen over the first 5 -min period $[F(3,20)=5.55, P<0.01]$ and, although this change was unidentified by post-hoc analysis, it also was probably due to an increase in climbing with (+)BW373U86 treatment alone. When naltrindole $(1 \mathrm{mg} / \mathrm{kg})$ was administered $30 \mathrm{~min}$ prior to (+)BW373U86, no significant difference was seen from vehicle alone during any period of the swim when examined using Dunnett's post-hoc analysis (Fig. 3b-e). Naltrindole alone also failed to produce significant changes when compared to vehicle
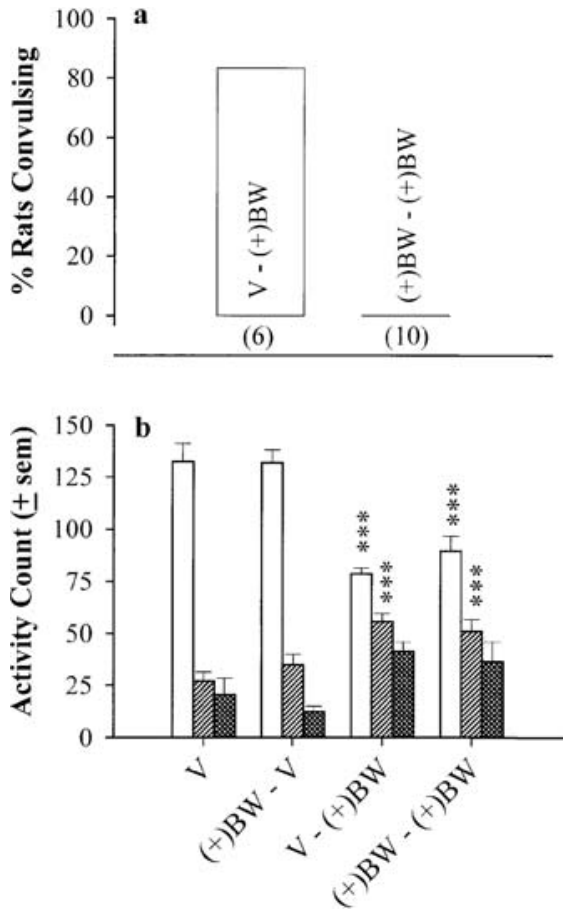

Fig. 4 The effect of tolerance development on (+)BW373U86 $[(+) B W]$-mediated a convulsions and $\mathbf{b}$ activity in the forced swim assay. Male Sprague-Dawley rats were injected with $10 \mathrm{mg} / \mathrm{kg}$ (+)BW373U86 (SC) or vehicle followed $24 \mathrm{~h}$ later with $10 \mathrm{mg} / \mathrm{kg}$ (+)BW373U86 (SC). a Rats were observed for convulsive behavior for $20 \mathrm{~min}$ after the second injection of (+)BW373U86 and then tested $60 \mathrm{~min}$ after that injection in the forced swim assay as described in Materials and methods. b Results from the forced swim assay are displayed for the total 15-min swim period. Clear bars denote immobility counts, single-hatched bars denote swimming counts and double-hatched bars denote climbing counts. Treatment groups are as follows: $V(+) B W 373$ U86 vehicle followed by $(+) B W 373$ U86 vehicle; $(+) B W-V \quad 10 \quad \mathrm{mg} / \mathrm{kg}$ $(+) B W 373$ U86 followed by $(+) B W 373$ U86 vehicle; $V-(+) B W$ (+)BW373U86 vehicle followed by $10 \mathrm{mg} / \mathrm{kg}(+) B W 373 \mathrm{U} 86$; $(+) B W-(+) B W 10 \mathrm{mg} / \mathrm{kg}(+) B W 373 \mathrm{U} 86$ followed by $10 \mathrm{mg} / \mathrm{kg}$ $(+) B W 373$ U86. $n=6$ for each group except $(+) B W-(+) B W$ where $n=10$. $* * * P<0.001$ when compared to vehicle $(V)$ alone by Dunnett's post-hoc analysis

alone. As data from the individual 5-min periods provided no additional observation from the $15 \mathrm{~min}$ total alone, only the 15-min total was analyzed for the remaining experiments.

As seen in mice (Comer et al. 1993), tolerance was fully evident to the convulsant effect of $10 \mathrm{mg} / \mathrm{kg}$ (+)BW373U86 (SC) $24 \mathrm{~h}$ after a single dose of $10 \mathrm{mg} /$ kg (+)BW373U86 (Fig. 4a). However, rats tolerant to the convulsant effect of $(+)$ BW373U86 still displayed an antidepressant-like profile of action in the forced swim assay (Fig. 4b). Both (+)BW373U86-naive and tolerant rats displayed a significant decrease in immobility $[F(3,24)=14.75, P<0.0001]$ and significant increase in swimming $[F(3,24)=5.93, P<0.01]$ when compared to vehicle alone over the total 15-min swim period (Fig. 4b). (+)BW373U86 had no effect when given as a $24 \mathrm{~h}$ pretreatment alone. 

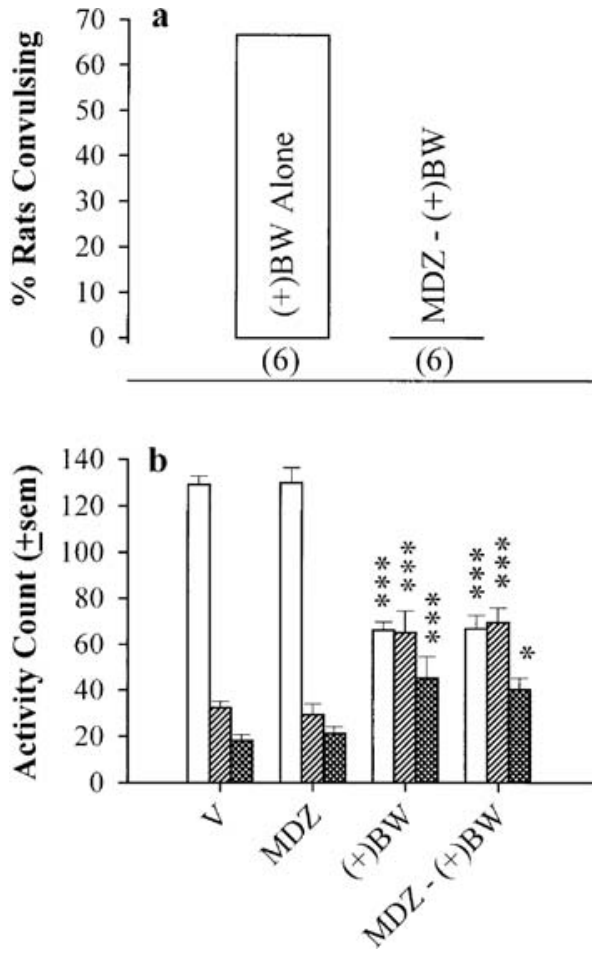

Fig. 5 The effect of midazolam (MDZ) on (+)BW373U86 $[(+) B W]$-mediated a convulsions and $\mathbf{b}$ activity in the forced swim assay. Male Sprague-Dawley rats were injected with $0.5 \mathrm{mg} / \mathrm{kg}$ midazolam (SC) followed 15 min later with $10 \mathrm{mg} / \mathrm{kg}$ (+)BW373U86 (SC). a Rats were observed for convulsive behavior for $20 \mathrm{~min}$ and then tested $60 \mathrm{~min}$ after (+)BW373U86 injection in the forced swim assay as described in Materials and methods. b Results from the forced swim assay are displayed for the total 15min swim period. Clear bars denote immobility counts, singlehatched bars denote swimming counts and double-hatched bars denote climbing counts. Treatment groups are as follows: $V$ MDZ vehicle followed by (+)BW373U86 vehicle; $M D Z 0.5 \mathrm{mg} / \mathrm{kg}$ MDZ followed by $(+) B W 373$ U86 vehicle; $(+) B W \mathrm{MDZ}$ vehicle followed by $10 \mathrm{mg} / \mathrm{kg}$ (+)BW373U86; $M D Z-(+) B W \quad 0.5 \mathrm{mg} / \mathrm{kg} \quad \mathrm{MDZ}$ followed by $10 \mathrm{mg} / \mathrm{kg}(+) B W 373$ U86. $n=6$ for each group. $* P<0.05$ and $* * * P<0.001$ when compared to vehicle $(V)$ alone by Dunnett's post-hoc analysis

Midazolam, when administered at a dose of $0.5 \mathrm{mg} / \mathrm{kg}$ (SC) 15 min prior to (+)BW373U86, completely prevented the convulsions and catalepsy of the $\delta$-opioid receptor agonist (Fig. 5a). However, midazolam did not alter the activity of (+)BW373U86 (Fig. 5b) in the forced swim assay. Both $(+)$ BW373U86 alone and midazolam pretreated (+)BW373U86 groups displayed a decrease in immobility over the total 15-min swim period $[F(3,20)=50.71, P<0.0001]$ (Fig. 5b). This decrease in immobility was coupled to an increase in swimming and climbing during the total 15 -min period [swimming: $F(3,20)=10.91, \quad P<0.001$; climbing: $\quad F(3,20)=6.22$, $P<0.01]$. No change was seen with midazolam alone when compared to vehicle alone.

\section{Discussion}

The $\delta$-opioid receptor agonists (+)BW373U86 and SNC80 both caused convulsions in rats as previously reported in mice (Comer et al. 1993; Hong et al. 1998). The convulsions were brief, non-lethal, and similar to those seen in mice, except that it was rare to see a complete rotation of the body around the longitudinal axis of the animal as is common in the mouse. On nearly all occasions, the convulsion involved the musculature of the head, neck, and forepaws, and in a few cases, the hindpaws. Following the convulsion, a period of catalepsy was seen, although Straub tail was not observed in rats. The dose ranges of the convulsant properties for both BW373U86 and SNC80 in rats were similar to those seen in mice. This potency relationship is consistent with in vitro potencies determined in binding assays at cloned $\delta$ opioid receptors (Negus et al. 1998). Finally, the latency to convulsion onset decreased with increasing dose, but was a little slower in rats than in mice (Comer et al. 1993). However, due to the similarity of the convulsant effects of these compounds and the fact that the convulsions are no more severe in rats than in mice, it is probable that the difference in latency to onset is due to slight species variation in the in vivo pharmacokinetic properties of the drugs.

Pharmacologically, the convulsant activity of the $\delta$ opioid receptor agonists in rats was the same as seen in mice. The convulsions produced by administration of $(+) B W 373$ U86 were fully blocked by the $\delta$-opioid receptor antagonist naltrindole. Also, tolerance developed to the convulsive effects of (+)BW373U86, consistent with findings in mice (Hong et al. 1998). The benzodiazepine, midazolam, also produced an antagonism of the convulsive effects of (+)BW373U86 in rats. This, again, is consistent with the studies in mice, whereby midazolam produced rightward and downward shifts in the doseeffect curves of BW373U86 and SNC80 (Comer et al. 1993; Hong et al. 1998). Thus, as well as being mediated through the $\delta$-opioid receptor, the convulsant effects of $\delta$ opioid receptor agonists are sensitive to modulation of GABAergic signaling in both rats and mice. Midazolam has been well described as producing its anticonvulsant effect by limiting seizuregenic activity within the CNS (Kubová et al. 1999) and thus it can be speculated that the lack of $\delta$-mediated convulsant activity after midazolam pretreatment is a direct consequence of decreased seizuregenic activity in these animals. Despite this fact, as electrical seizure activity was not measured directly in this study, some seizure activity may still be occurring in the midazolam-treated animals even though the convulsion was eliminated.

Comparisons of $\delta$-mediated convulsions in the rat with species other than mice are difficult. Although reports of individual convulsions can be found in squirrel and rhesus monkeys (Dykstra et al. 1993; Negus et al. 1994; Pakarinen et al. 1995), the data are insufficient to characterize the nature of the convulsions seen in these species. Interestingly, Spina and colleagues (1998), when 
examining the stereotypic and locomotor effects of nonpeptidic $\delta$-opioid receptor agonists in rats, did not observe convulsant activity. The highest doses used of either compound $(2.5 \mathrm{mg} / \mathrm{kg} \mathrm{BW} 373 \mathrm{U} 86$ and $10 \mathrm{mg} / \mathrm{kg} \mathrm{SNC80)}$ were lower than those observed to produce convulsant activity in the present study. However, wet-dog shakes and "falling on the back" were reported by Spina and colleagues (1998); these observations were consistent with the behavior exhibited by some rats in this study.

In the forced swim assay, (+)BW373U86 decreased immobility and increased swimming and climbing behaviors, consistent with an antidepressant-like effect, in a naltrindole-sensitive manner, indicating a $\delta$-opioid receptor-mediated mechanism of action. This observation is consistent with our previous studies with both SNC80 and (+)BW373U86 (Broom et al. 2002). However, the tolerance that developed to convulsant actions of (+)BW373U86 did not extend to the antidepressant-like activity. Animals tolerant to the convulsive effects of $\delta$ opioid receptor agonists showed the same activity in the forced swim assay as naive animals. Thus, it appears that the convulsant and antidepressant-like effects of $\delta$-opioid receptor agonists, although both mediated through the $\delta$ opioid receptor, are dissociable. This implication is strengthened by the fact that midazolam prevented the convulsant effects of $(+)$ BW373U86 but did not prevent its activity in the forced swim assay, suggesting that convulsions and GABAergic pathways do not play a major role in the antidepressant-like activity of (+)BW373U86.

The production of tolerance to the convulsant effect of (+)BW373U86 but not to that of the antidepressant-like effect beckons the question of whether tolerance would develop to the antidepressant-like effects of $\delta$-agonists upon repeated administration. Previous experiments suggest that upon administration of as little as three doses of SNC80 within $24 \mathrm{~h}$, tolerance may start to appear to the antidepressant-like properties of this compound (Broom et al. 2002). Therefore, a complete study is warranted as to the nature of tolerance development and its potential effect on antidepressant-like effects of $\delta$-agonists. Such a study may aid the understanding of the antidepressant-like mechanism of action of $\delta$-agonists as well as being of importance in the understanding of general $\delta$-opioid receptor pharmacology.

The present study demonstrates that $\delta$-mediated antidepressant-like activity in the rat forced swim assay does not require convulsant activity. Therefore, the mechanism of action of (+)BW373U86 and SNC80 in the forced swim assay is not based on an effect similar to electroconvulsive shock. It has previously been established that $\delta$-opioid receptor agonists cannot be readily categorized along with known antidepressant compounds due to their actions in the forced swim assay (Broom et al. 2002). In this way, the $\delta$-mediated antidepressant-like effect may be unique. Previous studies have indicated that antidepressant-like activity can be seen by modulating endogenous $\delta$-opioid systems. These have included the naltrindolereversible antidepressant-like effects of enkephalinase inhibitors such as RB101 and BL-2401 (Baamonde et al. 1992; Kita et al. 1997; Tejedor-Real et al. 1998) and studies with animals lacking the $\delta$-opioid receptor that displayed depression-like responses in various behavioral tests (Filliol et al. 2000).

The presence of convulsant activity was not noted in the studies examining the behavioral effects of the enkephalinase inhibitors; however, a thorough study is required. Although convulsions are not required for antidepressant-like activity with $\delta$-opioid receptor agonists, the contributions of seizure activity may be present and playing a role in this effect. This seems unlikely, however, as midazolam does not cause any attenuation of the antidepressant-like effect of $\delta$-agonists but blocks convulsions and probably decreases seizurogenic activity.

Subseizure stimulation of certain regions of the brain may be occurring with (+)BW373U86 to produce an effect similar to that of transcranial magnetic stimulation (TMS). TMS produces an antidepressant-like effect in the forced swim assay, possibly by stimulating specific brain regions without producing seizurogenic activity (Fleischmann et al. 1995; Zyss et al. 1997; Ji et al. 1998). These discoveries have led to speculation that the convulsion associated with ECS may be an unavoidable side effect of the large stimulation required for therapeutic effect (Ji et al. 1998). If correct, this hypothesis may also explain the mechanism of action of (+)BW373U86 with potential stimulation of certain CNS regions occurring in the absence of overt convulsant activity.

The present study demonstrates that the $\delta$-opioid receptor agonists SNC80 and (+)BW373U86 produce convulsions in rats. The convulsions are similar to those previously described in mice and are prevented by both naltrindole and midazolam, thereby implicating $\delta$-opioid receptor and GABAergic pathways in mediating this effect. Rapid tolerance develops to the convulsant effects of (+)BW373U86. Conversely, the antidepressant-like effect of (+)BW373U86, although naltrindole-sensitive, is not prevented by midazolam indicating that the GABAergic system is not playing a major role in modulating this effect. Finally, the development of tolerance to the convulsant effects of (+)BW373U86 does not change in the same manner as the putative antidepressant-like properties of this compound. The findings show that the antidepressant-like properties of (+)BW373U86, a nonpeptidic $\delta$-opioid receptor agonist, are dissociable from, and thus do not require, the convulsant activity of this compound.

Acknowledgements The authors wish to thank Carl Miller for help with the in vivo experiments. Research supported by USPHS grants DA00254, GM07767 and DA07267.

\section{References}

Baamonde A, Dauge V, Ruiz-Gayo M, Fulga IG, Turcaud S, Fournie-Zalushi M-C, Roques BP (1992) Antidepressant-type effects of endogenous enkephalins protected by systemic 
RB101 are mediated by opioid $\delta$ and dopamine $\mathrm{D}_{1}$ receptor stimulation. Eur J Pharmacol 216:157-166

Bilsky EJ, Calderon SN, Wang T, Bernstein RN, Davis P, Hruby VJ, McNutt RW, Rothman RB, Rice KC, Porreca F (1995) SNC80, a selective non-peptidic and systemically active opioid $\delta$ agonist. J Pharmacol Exp Ther 273:359-366

Bishop MJ, McNutt RW (1995) An efficient synthesis of the benzhydrylpiperazine $\delta$ opioid agonist (+)-BW373U86. Bioorg Med Chem Lett 5:1311-1314

Broom DC, Guo L, Coop A, Husbands SM, Lewis JW, Woods JH, Traynor JR (2000) BU48: a novel buprenorphine analog that exhibits $\delta$-opioid-mediated convulsions but not $\delta$-opioid-mediated antinociception in mice. J Pharmacol Exp Ther 294:11951200

Broom DC, Jutkiewicz EM, Folk JE, Traynor JR, Rice KC, Woods JH (2002) Non-peptidic $\delta$-opioid receptor agonists reduce immobility in the forced swim assay in rats. Neuropsychopharmacology 26:744-755

Calderon SN, Rothman RB, Porreca F, Flippen-Anderson JL, McNutt RW, Xu H, Smith LE, Bilsky EJ, Davis P, Rice KC (1994) Probes for narcotic receptor mediated phenomena. 19. Synthesis of $(+)-4-[(\alpha \mathrm{R})-\alpha-((2 \mathrm{~S}, 5 \mathrm{R})-4-$ allyl-2,5 dimethyl-1piperazinyl)-3-methoxybenzyl]-N,N-diethylbenzamide (SNC80): a highly selective, nonpeptide $\delta$ opioid receptor agonist. J Med Chem 37:2125-2128

Chang K-J, Rigdon GC, Howard JL, McNutt RW (1993) A novel, potent and selective non-peptidic $\delta$ opioid receptor agonist BW373U86. J Pharmacol Exp Ther 267:852-857

Comer SD, Hoenicke EM, Sable AI, McNutt RW, Chang K-J, DeCosta BR, Mosberg HI, Woods JH (1993) Convulsive effects of systemic administration of the $\delta$ opioid agonist BW373U86 in mice. J Pharmacol Exp Ther 267:127-134

Detke MJ, Rickels M, Lucki I (1995) Active behaviors in the rat forced swimming test differentially produced by serotonergic and noradrenergic antidepressants. Psychopharmacology 121:66-72

Dykstra LA, Schoenbaum GM, Yarbrough J, McNutt R, Chang K-J (1993) A novel $\delta$ opioid agonist, BW373U86, in squirrel monkeys responding under a schedule of shock titration. J Pharmacol Exp Ther 267:875-882

Emrich HM, Hollt V, Kissling W, Fischler M, Laspe H, Heinemann $\mathrm{H}$, von Zerssen D, Herz A (1979) $\beta$-Endorphin-like immunoreactivity in cerebrospinal fluid and plasma of patients with schizophrenia and other neuropsychiatric disorders. Pharmakopsychiatr Neuro-Psychopharmakol 12:269-276

Filliol D, Ghozland S, Chluba J, Martin M, Matthes HWD, Simonin F, Befort K, Gaveriaux-Ruff C, Dierich A, LeMeur M, Valverde O, Maldonado R, Kieffer BL (2000) Mice deficient for $\delta$ - and $\mu$-opioid receptors exhibit opposing alterations of emotional responses. Nature Genet 25:195-200
Fleischmann A, Prolov K, Abarbanel J, Belmaker RH (1995) The effect of transcranial magnetic stimulation of rat brain on behavioral models of depression. Brain Res 699:130-132

Hong EJ, Rice KC, Calderon S, Woods JH, Traynor JR (1998) Convulsive behavior of nonpeptide $\delta$-opioid ligands: comparison of SNC80 and BW373U86 in mice. Analgesia 3:269-276

Inturrisi CE, Alexopoulos G, Lipman R, Foley K, Rossier J (1982) $\beta$-Endorphin immunoreactivity in the plasma of psychiatric patients receiving electroconvulsive treatment. Ann NY Acad Sci 398:413-423

Ji R-R, Schlaepper TE, Aizenman CD, Epstein CM, Qiu D, Huang JC, Rupp F (1998) Repetitive transcranial magnetic stimulation activates specific regions in rat brain. Proc Natl Acad Sci USA 95:15635-15640

Kita A, Imano K, Seto Y, Yakuo I, Deguchi T, Nakamura H (1997) Antinociceptive and antidepressant-like profiles of BL-2401, a novel enkephalinase inhibitor, in mice and rats. Jpn J Pharmacol 75:337-346

Kubová H, Mocková M, Mareš P (1999) Midazolam suppresses spike-and-wave rhythm accompanying three different models of epileptic seizures. Physiol Res 48:491-500

Negus SS, Butelman ER, Chang K-J, DeCosta B, Winger G, Woods JH (1994) Behavioral effects of the systemically active $\delta$ opioid agonist BW373U86 in rhesus monkeys. J Pharmacol Exp Ther 270:1025-1034

Negus SS, Gatch MB, Mello NK, Zhang X, Rice KC (1998) Behavioral effects of the $\delta$-selective opioid agonist SNC80 and related compounds in rhesus monkeys. J Pharmacol Exp Ther 286:362-375

Pakarinen ED, Woods JH, Moerschbaecher JM (1995) Repeated acquisition of behavioral chains in squirrel monkeys: comparisons of a $\mu, \kappa$ and $\delta$ opioid agonist. J Pharmacol Exp Ther 272:552-559

Porsolt RD, Le Pichon M, Jalfre M (1977) Depression: a new animal model sensitive to antidepressant treatments. Nature 266:730-732

Reneric J-P, Lucki I (1998) Antidepressant behavioral effects by dual inhibition of monoamine reuptake in the rat forced swimming test. Psychopharmacology 136:190-197

Spina L, Longoni R, Mulas A, Chang K-J, Di Chiara G (1998) Dopamine-dependent behavioural stimulation by non-peptide $\delta$ opioids BW373U86 and SNC 80: 1. locomotion, rearing and stereotypies in intact rats. Behav Pharmacol 9:1-8

Tejedor-Real P, Mico JA, Smadja C, Maldonado R, Roques BP, Gilbert-Rahola J (1998) Involvement of $\delta$-opioid receptors in the effects induced by endogenous enkephalins on learned helplessness model. Eur J Pharmacol 354:1-7

Zyss T, Gorka Z, Kowalska M, Vetulani J (1997) Preliminary comparison of behavioral and biochemical effects of chronic transcranial magnetic stimulation and electroconvulsive shock in the rat. Biol Psychiatry 42:920-924 